\title{
Male Obesity: Epigenetic Origin and Effects in Sperm and Offspring
}

\author{
Sam Houfflyn ${ }^{1} \cdot$ Christophe Matthys $^{2} \cdot$ Adelheid Soubry $^{1}$
}

Published online: 9 November 2017

(C) Springer International Publishing AG 2017

\begin{abstract}
Purpose of Review The prevalence of obesity has increased substantially in the current generations of Western countries, and the burden of obesity-related complications has been growing steadily. In men, obesity is not only a major risk factor for serious chronic diseases, concern is growing that the reproductive capacity, and more particularly, their offspring's health may be affected. Obesity-related impaired spermatogenesis is associated with a decrease in microscopic and molecular sperm characteristics and pregnancy success. We hypothesize that epigenetics is an important mediator explaining interactions between an obesogenic environment and sperm/offspring outcomes.

Recent Findings Recent studies have explored inter- and transgenerational epigenetic effects in sperm cells and in offspring. Father-to-child effects have been reported in relation to preconceptional nutritional and life-style related factors.

Summary Here, we summarize the current understanding about obesity and molecular or epigenetic underlying mechanisms in sperm. We identify the obesogenic environment of
\end{abstract}

This article is part of the Topical Collection on Epigenetics

Adelheid Soubry

adelheid.soubry@hotmail.com

Sam Houfflyn

sam.houfflyn@student.kuleuven.be

Christophe Matthys

christophe.matthys@uzleuven.be

1 Epidemiology Research Unit, Department of Public Health and Primary Care, University of Leuven, 3000 Leuven, Belgium

2 Clinical and Experimental Endocrinology, Department of Chronic Diseases, Metabolism, and Ageing, KU Leuven University, Leuven, Belgium the father before conception as a potential origin of health or disease in the offspring and include it as part of a new concept, the Paternal Origins of Health and Disease (POHaD).

Keywords Obesity · Environment · Male fertility · Sperm · Fathers $\cdot$ Epigenetics $\cdot$ Offspring health

\section{Introduction}

Overweight and obesity are defined as abnormal or excessive fat accumulation that impairs health. The World Health Organization (WHO) classifies adults with a BMI $\left(\mathrm{kg} / \mathrm{m}^{2}\right)$ equal to or greater than 25 as overweight and a BMI equal to or greater than 30 as obese. In general, a high BMI is a major risk factor for various metabolic changes such as glucose intolerance, insulin resistance, hyperleptinaemia, and hypogonadism in men [1,2]. Co-morbidities associated with obesity are increased risk of cerebrovascular diseases, cardiovascular disease, type 2 diabetes, and cancer. Since 1980, obesity has more than doubled worldwide. WHO data of 2014 show that the USA takes the lead with a prevalence of $72.8 \%$ obese or overweight adult men. Nearly half of them have been classified as obese (or $33.6 \%$ of the US male population) [3].

In this review, we first discuss (epi) genetic origins of obesity and related environment. Environmental factors that do not change the DNA sequence can instead alter the epigenome causing increased risk for chronic diseases, including metabolic disorders and obesity [4]. In brief, the epigenome encompasses regulatory information that acts through histone modifications, the function of non-coding RNAs, and DNA methylation, a chemical process that adds a methyl group to DNA. This occurs at a $\mathrm{CpG}$ site, where a cytosine nucleotide is located next to a guanine nucleotide linked by a phosphate 
$[5,6]$. Depending on its methylation status, genes can be turned on or off. In this way, metabolic and other important pathways can affect homeostasis in the body and result in phenotypic changes relatively quickly.

We further describe the current knowledge on microscopic and molecular characteristics of sperm in relation to obesity. In order to understand the role of the epigenome as a potential key mediator, we include some epigenetic findings. Finally, we explore the epigenetic effects of obesity in sperm. This is also summarized in a hypothetic and schematic overview in Fig. 1.

\section{Obesity: Genetic and Epigenetic Origins?}

Supposing that "Darwinian evolution" took place in an "energy-poor" environment, the genetic legacy that promotes obesity may have been a protective factor for survival in ancient human history [7]. As a result, the majority of people nowadays seem to have a combination of obesitysusceptibility genes, while others seem to be relatively resistant to overweight and obesity despite living in the same environment [7]. Body mass variation is known to have a large genetic component; heritability of BMI ranges between 30 and $70 \%$ [8]. Several major genes contribute to obesity by disrupting the hypothalamic pathways controlling satiety and food intake. However, alterations in these genes such as leptin (LEP), leptin receptor (LEPR), and Melanocortin 4 receptor (MC4R) are relatively rare [9]. Instead, several molecular pathways are involved in obesity and it has been considered as polygenic in origin. Disturbed biological functions in energy expenditure, lipid and glucose metabolism, and adipose tissue development and inflammation have been related to obesity [10]. However, despite reported relations between multi-genetic variations and BMI, the sudden increase of obesity rates has occurred only recently. After World War II, industrialization and economic growth led to an increasingly urbanized and sedentary workforce [7]. Coupled with ease of access to food, this basic reduction in energy expenditure and increase in caloric intake has contributed to what is now termed the "obesogenic" environment [8]. Although the interplay between nutritional intake and energy expenditure is the main aspect in regulating bodyweight, many indirect lifestyle factors and other environmental traits contribute to an individual's susceptibility of becoming over weighted or obese. Although some "indirect factors" need further proof of a causal relation, examples include stress, depression, sleep deprivation, medication, and obesogenic factors such as organic chlorine derivatives and endocrine disruptors from food packaging. As a result of individual differences in genetic legacy, some individuals are not or less able to keep a stable and healthy body weight in the current "Western" environment. The accumulation or a cocktail of multiple environmentally harmful exposures may be the reason why our world is facing a rapid increase in obesity rates.

Evidence suggests that the environment can change molecular or epigenetic profiles in the exposed individual, ultimately resulting in obesity (Fig. 1). For instance, nutritional factors, which do not change the genome, can instead alter DNA methylation causing increased risk for chronic diseases or obesity [4]. The epigenome is supposed to react quite rapidly to environmental changes, compared to adaptation through genetic variation. Conversely, a recent report by Wahl et al. suggests that adiposity may also influence DNA methylation $[11 \bullet]$. The testes are an organ of rapidly growing cells that is susceptible to epigenetic changes (or damage) [12•] (Fig. 1).

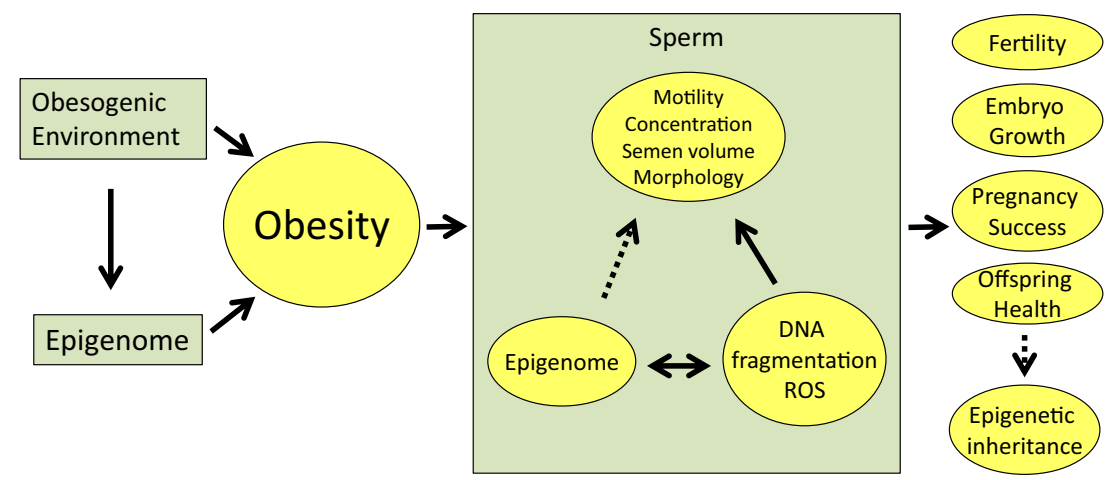

Fig. 1 Hypothetical overview of obesity-related associations with sperm characteristics and the role of the epigenome. Obesity is a result of several environmental exposures, summarized as the obesogenic environment. The fundamental cause of obesity or excessive body fat can be found in an imbalance between consumed and expended energy. Although this is a simple concept, the metabolic system balancing energy intake and expenditure is complex and is not fully understood. Epigenetic mechanisms play a role in this regulatory system, and the epigenome itself is susceptible to environmental factors as well. Obesity causes sperm aberrancies at the level of chromatin, DNA, ROS, epigenetic factors, morphology, and other clinical characteristics. The mechanisms of interaction between these molecular and physical features of sperm are largely unknown. Some associations have been reported (arrows). But, it is unclear if clinical sperm characteristics are affected by epigenetic changes (dashed arrow). The acquired sperm aberrancies can ultimately result in fertility problems or disorders in the offspring. The next question rises if this epigenetic "message" will be retained in future generations 
Wahl et al.'s epigenome-wide study provided a link between BMI and widespread changes in DNA methylation in humans [11 $\cdot$. A potential role of the epigenome in pathogenesis of obesity-related issues has been suggested, and the authors concluded that disturbances in DNA methylation may predict future development of chronic diseases, such as diabetes type $2[11 \bullet]$. Other epigenetic alterations related to obesity are situated at the level of the germ line. It is hypothesized that the epigenetic plasticity allows the environment to leave a mark on the germ line, which can be passed on to the next genera$\operatorname{tion}(\mathrm{s})[13 \cdot]$.

\section{Obesity and the Male Germ Line}

\section{Effects of Obesity on Sperm Quality}

Currently, biomarkers to predict male fertility include standard clinical sperm tests, such as semen volume, sperm concentration, motility, progression, morphology, leukocyte quantification, and some other characteristics, such as liquefaction, viscosity, $\mathrm{PH}$, and color. Cutoff reference values for these characteristics have been defined by the WHO [14, 15]. Studies focusing on the impact of obesity on these variables do not always obtain similar results. A study in Denmark including 1558 military recruits showed that overweight men had a 21 and $24.9 \%$ reduction in sperm concentration and total sperm count, respectively. Normal motility and semen volume were unaffected [16]. Belloc et al. published a large single-centre study (10,665 men) on the potential impact of BMI on sperm characteristics. They reported a significant association between obesity and volume, concentration and total sperm count after adjustment for male age and abstinence duration. It should be noted that BMI was self-reported and most subjects were seeking medical advice in the fertility clinic because of fertility issues [17].

The effective and causal relation between BMI and clinical sperm tests remains controversial. Recent meta-analyses reported opposing conclusions. Sermondade et al. evaluated 21 studies, representing a sample size of about 13,000 men. They showed that obese men had higher odds for oligozoospermia (OR was 1.42; CI 95\%, 1.12-1.79) or azoospermia (OR was 1.81; CI 95\%, 1.23-2.66), compared to men with normal weight [18]. A review by MacDonald et al. included 31 studies, of which 5 were suitable for a meta-analysis of BMI and standard clinical semen tests, representing nearly 5000 participants. Paternal obesity was not associated with standard sperm counts, including concentration, sperm count, volume, and motility [19]. A meta-analysis published by Campbell et al. included 30 papers, with a total of about 115,000 participants. Obese men were more likely to experience infertility and had an increased percentage of sperm with low-mitochondrial membrane potential, DNA fragmentation, and abnormal morphology [20].

Besides BMI, some studies also included body fat distribution such as waist and hip circumference, to search for associations with sperm characteristics. Eisenberg et al. found that waist circumference was inversely correlated with semen volume and total sperm count in men who did not have fertility problems [21]. Fejes et al. found that waist circumference of infertile men was negatively correlated with progressive motile sperm count [22]. Others also reported a negative association between waist circumference, sperm concentration, and total motile sperm count [23]. Interestingly, an intervention study provided evidence that adverse sperm characteristics related to obesity are reversible. Häkonsen et al. showed in 43 men with a BMI $>33 \mathrm{~kg} / \mathrm{m}^{2}$ that a 3 - to 4-month weight loss program increased total sperm count and semen volume. These results were accompanied by an improvement in sex hormone profiles [24]. However, it is difficult to discern whether these effects resulted from body fat loss, lifestyle intervention, or both [24]. Reis et al. were not able to confirm these findings in bariatric patients. They found no changes 2 years after ten morbidly obese patients had undergone bariatric surgery and concluded that sperm counts do not recover well after an extensive body fat reduction in this particular subgroup [25]. Interestingly, case series have reported a reduction in sperm counts in a period of 12 to 18 months after bariatric surgery. This may be due to nutritional deficiencies and the elevated release of toxins $[18,26]$.

Nutritional factors, such as consumption of high-energy diets (HEDs), have also been related to impaired sperm concentration, motility, and morphology [27•]. Jensen et al. also investigated the association between dietary fat intake and sperm quality. A higher intake of saturated fat was associated with significantly lower sperm concentration and total sperm count [28]. Another study also found a negative correlation between dietary trans fatty acid intake and sperm concentration [29].

\section{Effects of Obesity on Male Fertility and Offspring}

Successful pregnancy rates and live birth rates are often used as key endpoints to define fertility. Epidemiologic studies have demonstrated that a high-paternal BMI increases time to pregnancy $[30,31]$ and decreases clinical pregnancy rates $[32,33]$. Time to pregnancy is even higher if both man and woman were overweight or obese [31]. In men, it is well known that obesity and redundant fat mass have a noticeably negative impact on his reproductive system. Conversion of androgens into estrogens in adipose tissue of obese men causes a sexual hormone imbalance, resulting in hypogonadism. Furthermore, adipose tissue produces pro-inflammatory cytokines (such as IL-6 and TNF-alpha) and oxidative stress in the male reproductive 
tract. Others have widely documented and discussed the link between obesity and hormonal profiles [34-36], as well as obesity-related inflammatory responses [37-39]. We here focus on obesity-related effects in sperm that have been linked with (transgenerational) epigenetic effects. This is particularly interesting; it is currently unclear how male obesity affects the sperm epigenome and in utero development. Furthermore, according to a growing body of literature, if pregnancy succeeds, paternal obesity or nutritional conditions may influence offspring health $[12 \bullet, 13 \bullet, 40-48]$.

\section{Effects of Obesity on Molecular Composition of Sperm}

\section{DNA Fragmentation}

Besides the effects of BMI on classical sperm parameters, more recent literature includes the molecular composition of sperm cells. This is assessed by evaluating the degree of DNA fragmentation and/or oxidative stress. Several studies report the DNA fragmentation index (DFI) or the percentage of sperm that has increased levels of double or single-strand breaks in nuclear DNA. DFI is often used as an indicator of pregnancy success. In healthy men, DFI is 3 to $5 \%$, while a DFI of 30\% or higher is associated with reduced fertility [49]. Obesity and overweight have been related to a high DFI or to DNA/chromatin damage in sperm cells [50-52]; suggesting an obesity-related effect on the molecular composition of sperm. A meta-analysis showed also a link between sperm DNA damage and increased pregnancy loss [53]. However, Zini et al. could not link their observation with embryo quality or early growth.

\section{Reactive Oxygen Species}

DNA damage is a downstream effect of increased cellular oxidative stress. For instance, infertile men present higher levels of oxidative DNA damage in spermatozoa, including high levels of 8-hydroxy-20-deoxguanosine, which is a major oxidized base adduct formed in sperm cells when DNA is targeted by an excess of reactive oxygen species (ROS). It is well documented that the degree of oxidative stress can be evaluated through measurement of ROS. These are unstable chemical species containing oxygen such as peroxides, superoxide, hydroxyl radicals, and singlet oxygen. Major sources of ROS production in sperm cells are their plasma membrane and mitochondria [54]. Other potential sources of ROS in seminal fluid are macrophages and polymorphonuclear leukocytes [55]. It should be noted that ROS are also considered normal by-products of the cellular metabolism. However, a state of oxidative stress occurs when ROS production is uncontrolled and/or ROS scavenger system is inefficient.
Sperm cells have a high number of mitochondria because of their motile capacities. DNA of these organelles or mitochondrial DNAs (mtDNAs) in particular are extremely sensitive to oxidative stress. Furthermore, mutations at the level of mtDNAs exacerbate the function of the electron transport chain (ETC), which also contributes to an increase in ROS production. Furthermore, spermatozoa are extremely prone to oxidative injury because they are relatively deficient in ROS-scavenger enzymes. In brief, these factors cause them to be largely dependent on the antioxidant protection that exists within the testicular milieu and throughout the male reproductive tract [56].

Relations between obesity, ROS, and sperm characteristics have been investigated by several research groups, both in animal models and in humans. Studies in animal models have shown that impaired spermatogenesis linked to HED consumption can be attributed to unbalanced ROS generation. In response to high-energy intake, beta-oxidation in the testes increases [57]. Interestingly, rats fed with HED have lower expression of two key inducers of ROS-detoxifying enzymes. This contributes to a decrease in testicular ROS-defense, which is associated with a deficient mitochondrial function, causing compromising testicular bio-energetic capacity and a decline in sperm quality [58]. In humans, Tunc et al. could partially confirm this observation. They reported a positive association between BMI and ROS, but no correlation was found between ROS and sperm DNA integrity or motility. Noteworthy, their study included a small number of participants (only 81 men) [59]. Effects from a high-fat paternal diet on ROS and sperm DNA damage have been confirmed by others $[60,61]$. The production of ROS has generally been accepted to negatively affect sperm motility and potentially to lead to damage of DNA or other important structures such as plasma membranes [62, 63].

Other dietary factors such as low-protein and high-sugar intake have been associated with obesity and ROS production. While little is known about the possible influences of protein intake on male fertility, high-sugar intake is known to affect male reproductive function. In a cross- sectional study of 189 young men (18-22 years old), sugarsweetened beverages (SSB) were associated with lower sperm motility. Interestingly, this association was not mediated by an increased BMI. The effect was only observed in lean people and not in overweight or obese people. This can be due to a true biological interaction where a strong detrimental effect of excess body weight on motility outweighs the relation between SSB and poor semen quality. Therefore, the relation between SSB and poor semen quality can only be observed among men with normal BMI who already had a higher baseline semen quality [64]. Although results of this cross-sectional design should be interpreted with care, a possible explanation could be that sugar intake increases insulin resistance, which in turn 
increases oxidative stress $[65,66]$. As indicated earlier, elevated levels of oxidative stress can result in sperm DNA damage, lipid peroxidation, and reduced motility $[67,68]$. Ruff et al. in 2013 confirmed in a mice model that sugar intake affects male reproductive function. Male mice who consumed $25 \mathrm{EN} \%$ of a glucose/fructose mixture, modeling high-fructose corn syrup had 25\% fewer offspring than control male mice [69].

It has been shown that in addition to DNA damage through direct attack of free radicals on DNA molecules, ROS signaling is an important factor of epigenetic processes such as DNA methylation and histone modification. Although the exact mechanism is not known, this suggests how HED consumption can be captured in the sperm epigenome and thereby possibly affect health of the offspring [70]. To our knowledge, no human data are available on epigenetic effects in sperm from a "high-carbohydrate diet" or sugar-rich diet.

An increasing number of reports also highlight the existence of a complex interplay between cytokines and ROS. Some cytokines can stimulate pro-oxidant and antioxidant systems and influence the generation of ROS. On the other hand, ROS can also promote production of cytokines [26, 71, 72]. In the current review, we do not further elaborate on this subject, but focus on the epigenetic components.

\section{Transgenerational Epigenetic Consequences of Paternal Obesity on the Germ Line}

As described above, obesity results from a range of environmental factors, including but not limited to dietary and lifestyle factors. These factors can alter epigenetic patterns, increase the risk of chronic diseases and change phenotypic characteristics of the individual, but future generations can also be affected.

The first evidence for obesity-related effects from father to offspring was published by $\mathrm{Ng}$ et al. They reported that paternal high-fat diet (HFD) exposure programs $\beta$-cell dysfunction in rat F1 female offspring [73]. Female offspring of HFD fathers had an early onset of impaired insulin secretion and glucose tolerance worsened over time, compared to offspring from control fathers. DNA methylation changes were measured in a key pancreatic islet gene, Ill3ra2, in these offspring. In 2014, $\mathrm{Ng}$ et al. added that the transcriptome of retroperitoneal white adipose tissue of offspring rat was also concomitantly affected [74]. However, no analyses were performed on germ cells of males. Genetic association analyses suggest that the epigenome of multiple tissues is influenced by adiposity [11•]. Hence, developing sperm cells may be one of tissues carrying methylation changes. Epigenetic changes in the male gametes may be the underlying cause of these transgenerational effects.

Fullston et al. investigated the effect of diet-induced paternal obesity on the molecular profiles of testes and sperm. Male mice fed on a HFD showed altered microRNA content in mature sperm and a $25 \%$ reduction in global methylation of germ cell DNA [75]. Palmer et al. evaluated the presence of Sirtuin-6 (SIRT6), a histone deacetylase, in testicular germ cells throughout spermatogenesis in mice. They measured the effects of diet-induced obesity with HFD on SIRT6 levels and activity. SIRT6 levels were significantly decreased in mice that were fed with HFD. This was also associated with increased damage of sperm DNA [76]. Terashima et al. examined the effects of HFD on chromatin of spermatozoa in mice [77]. They investigated $\mathrm{H} 3$ retention and genomic imprints at seven imprinted loci in sperm. Additionally, they examined liver gene expression in male offspring. They did not find any changes in DNA methylation associated with a high-fat diet [77]. Instead, they detected differential histone H3-occupancy at genes involved in the regulation of embryogenesis and differential $\mathrm{H} 3 \mathrm{~K} 4 \mathrm{me}$ 1-enrichment at transcription regulatory genes in HFD fathers. Compared to controls, the hepatic mRNA level of seven genes (out of 20 evaluated) was significantly altered in HFD male offspring.

Protein restriction in rodents affects sperm small RNA (sRNA) levels, including transfer RNAs (tRNAs) [78]. Grandjean et al. in 2015 demonstrated that microinjection of extracted RNA from mice testis that received a Western-like diet into zygotes resulted in a metabolic phenotype in the offspring similar to that of offspring from males who were administered a Western-like diet [79••]. Similarly, Chen et al. demonstrated that injection of transfer RNA-derived small RNAs (tsRNA) originating from sperm from HFD mice males into normal zygotes caused differential expression of genes that belong to metabolic pathways. This was measured in early embryos, but offspring showed metabolic disorders as well [80॰].

In humans, studies on potential effects of obesity and overnutrition on sperm epigenetics are limited. For instance, to our knowledge, no human studies have explored a function of RNA fragments in the transmission of dietary conditions from father to child. Consales et al. investigated the impact of demographic and lifestyle factors on sperm global methylation levels in 269 healthy men. Global DNA methylation levels were quantified in repetitive DNA sequences (LINE-1, Sat $\alpha$, and Alu). No correlation was found between BMI and sperm DNA methylation [81]. Smoking was the only factor that showed a significant positive association with the LINE1 methylation level. Alu and Sat $\alpha$ methylation levels were not associated with lifestyle factors.

However, when exploring DNA methylation at an individual gene level or in genome-wide studies, differential methylation by obesity-status has been reported. For instance, in sperm from a population of 69 young and healthy volunteers, DNA methylation percentages were found to be significantly different in obese or overweight men versus normal weight 
men at differentially methylated regions (DMRs) of imprinted genes [82•]. Donkin et al. provided a comprehensive epigenetic approach on sperm samples from obese and lean Danish men and confirmed an association between obesity and epigenetic differences in sperm cells [83•]. Unfortunately, only 10 obese and 13 lean men were included and not all epigenetic analyses were performed in all samples. An interesting finding was that bariatric treatment resulted in significant epigenetic changes in sperm cells. Here too, the study cohort was small: only six bariatric patients were followed.

Epigenetic changes can persist for multiple generations, predisposing the offspring with a different methylation pattern and altered molecular programming [12•, 13•, 45, 84]. Altered methylation profiles at multiple imprint regulatory regions in children born to obese parents were detected after comparison with DNA methylation profiles of children born to non-obese parents $[85 \bullet, 86]$. Subsequently, in a separate study, altered DNA methylation percentages at several differentially methylated regions were also detected in sperm, suggesting that the male overweight/obesity status is traceable in the sperm epigenome [82•].

\section{Conclusion}

We hypothesized that an obesogenic environment not only causes phenotypic changes such as predisposition to obesity in the individual, but it can also affect sperm quality, pregnancy success, and offspring health. In response to obesity-related factors, several cellular pathways and mechanisms are activated. The interplay between epigenetic changes, molecular, and physiological aspects in sperm becomes apparent in fertility rates and developmental outcomes. Hence, epigenetic changes that have occurred in the germ line can be passed on to future generation(s). Besides well-documented maternal and in utero influences, we are now reaching a new era in which the environment of future fathers will become relevant as well. This issue has currently been one of the major questions in the new and intriguing field of transgenerational epigenetics, given that it reflects an important concern society is faced with. Currently, future fathers are not involved in any life-style related preconceptional recommendations. However, if obesity can be shown to be a new determinant contributing to the development of detrimental health conditions in offspring, this may well need to change. The current concepts of the Developmental Origins of Health and Disease (DOHaD) are being used to guide policies that support mother and children's health. However, it is of public interest to explore both the maternal and the paternal segment of the DOHaDrelated research. The latter has recently been coined as the Paternal Origins of Health and Disease or "POHaD."
Acknowledgements Many thanks to Herlinda Vekemans for editing the text. This work was supported by a research grant from KU Leuven University (OT/14/109).

\section{Compliance with Ethical Standards}

Conflict of Interest Sam Houfflyn, Christophe Matthys, and Adelheid Soubry declare no potential conflicts of interest.

Human and Animal Rights and Informed Consent This article contains no studies with human or animal subjects performed by any of the authors.

\section{References}

Papers of particular interest, published recently, have been highlighted as:

- Of importance

- Of major importance

1. Du Plessis SS, Cabler S, McAlister DA, Sabanegh E, Agarwal A. The effect of obesity on sperm disorders and male infertility. Nat Rev Urol. 2010;7(3):153-61.

2. Gonzalez-Muniesa P, Martinez-Gonzalez MA, FB H, Despres JP, Matsuzawa Y, Loos RJF, et al. Obesity. Nat Rev Dis Primers. 2017;3:17034. https://doi.org/10.1038/nrdp.2017.34.

3. WHO. WHO fact sheets: obesity an overweight. http://www.who. int/mediacentre/factsheets/fs311/en/access date Sept. 1, 2017.

4. Jirtle RL, Skinner MK. Environmental epigenomics and disease susceptibility. Nat Rev Genet. 2007;8(4):253-62. https://doi.org/ 10.1038/nrg2045.

5. Egger G, Liang G, Aparicio A, Jones PA. Epigenetics in human disease and prospects for epigenetic therapy. Nature. 2004;429(6990):457-63. https://doi.org/10.1038/nature02625.

6. Robertson KD. DNA methylation and chromatin - unraveling the tangled web. Oncogene. 2002;21(35):5361-79. https://doi.org/10. 1038/sj.onc.1205609.

7. Bellisari A. Evolutionary origins of obesity. Obes Rev. 2008;9(2): 165-80. https://doi.org/10.1111/j.1467-789X.2007.00392.x.

8. Bell CG, Walley AJ, Froguel P. The genetics of human obesity. Nat Rev Genet. 2005;6(3):221-34. https://doi.org/10.1038/nrg1556.

9. Farooqi IS, O'Rahilly S. New advances in the genetics of early onset. Obesity. 2005;1149-52.

10. Mutch DM, Clement K. Genetics of human obesity. Best Pract Res Clin Endocrinol Metab. 2006;20(4):647-64. https://doi.org/10. 1016/j.beem.2006.09.006.

11. Wahl S, Drong A, Lehne B, Loh M, Scott WR, Kunze S, et al. Epigenome-wide association study of body mass index, and the adverse outcomes of adiposity. Nature. 2017;541(7635):81-6. https://doi.org/10.1038/nature20784. An epigenome-wide study that investigates potential relationships between DNA methylation and BMI, providing new insights into the biological pathways influenced by obesity. Development of chronic disorders or other future harmful outcomes could be predicted.

12. Soubry A, Hoyo C, Jirtle RL, Murphy SKA. Paternal environmental legacy: evidence for epigenetic inheritance through the male germ line. BioEssays. 2014. https://doi.org/10.1002/bies. 201300113. Defining susceptibility windows to environmental influences and epigenetic changes in the time-course of the development of male germ cells. 
13. Soubry A. Epigenetic inheritance and evolution: a paternal perspective on dietary influences. Prog Biophys Mol Biol. 2015;118(1-2): 79-85. https://doi.org/10.1016/j.pbiomolbio.2015.02.008. Explaining a role for the male germ line as one of nature's tools to capture messages from our diet and to transfer this information to subsequent (and multiple) generations.

14. Esteves SC. Clinical relevance of routine semen analysis and controversies surrounding the 2010 World Health Organization criteria for semen examination. Int Braz J Urol. 2014;40(4):443-53.

15. Cooper TG, Noonan E, von Eckardstein S, Auger J, Baker HW, Behre HM, et al. World Health Organization reference values for human semen characteristics. Hum Reprod Update. 2010;16(3): 231-45. https://doi.org/10.1093/humupd/dmp048.

16. Jensen TK, Andersson A-M, Jorgensen N, Andersen A-G, Carlsen E, Petersen $\mathrm{JH}$, et al. Body mass index in relation to semen quality and reproductive hormones among 1,558 Danish men. Fertil Steril. 2004;82(4):863-70. https://doi.org/10.1016/j.fertnstert.2004.03.056.

17. Belloc S, Cohen-Bacrie M, Amar E, Izard V, Benkhalifa M, Dalléac A, et al. High body mass index has a deleterious effect on semen parameters except morphology: results from a large cohort study. Fertil Steril. 2014;102(5):1268-73. https://doi.org/10.1016/j. fertnstert.2014.07.1212.

18. Sermondade N, Faure C, Fezeu L, Shayeb AG, Bonde JP, Jensen TK, et al. BMI in relation to sperm count: an updated systematic review and collaborative meta-analysis. Hum Reprod Update. 2013;19(3):221-31. https://doi.org/10.1093/humupd/dms050.

19. aa MD, Herbison GP, Showell M, Farquhar CM. The impact of body mass index on semen parameters and reproductive hormones in human males: a systematic review with meta-analysis. Hum Reprod Update. 2010;16(3):293-311. https://doi.org/10.1093/ humupd/dmp047.

20. Campbell JM, Lane M, Owens JA, Bakos HW. Paternal obesity negatively affects male fertility and assisted reproduction outcomes: a systematic review and meta-analysis. Reprod BioMed Online. 2015;31(5):593-604. https://doi.org/10.1016/j.rbmo.2015.07.012.

21. Eisenberg ML, Kim S, Chen Z, Sundaram R, Schisterman EF, Buck Louis GM. The relationship between male BMI and waist circumference on semen quality: data from the LIFE study. Hum Reprod (Oxford, England). 2014;29(2):193-200. https://doi.org/10.1093/ humrep/det428.

22. Fejes I, Koloszár S, Szöllosi J, Závaczki Z, Pál A. Is semen quality affected by male body fat distribution? Andrologia. 2005;37(5): 155-9. https://doi.org/10.1111/j.1439-0272.2005.00671.x.

23. Hammiche F, Laven JSE, Twigt JM, Boellaard WPA, Steegers EAP, Steegers-Theunissen RP. Body mass index and central adiposity are associated with sperm quality in men of subfertile couples. Hum Reprod. 2012;27(8):2365-72. https://doi.org/10.1093/humrep/ des177.

24. Håkonsen L, Thulstrup A, Aggerholm A, Olsen J, Bonde J, Andersen $\mathrm{C}$, et al. Does weight loss improve semen quality and reproductive hormones? Results from a cohort of severely obese men. Reprod Health. 2011;8(1):24. https://doi.org/10.1186/17424755-8-24.

25. Reis LO, Zani EL, Saad RD, Chaim EA, de Oliveira LC, Fregonesi A. Bariatric surgery does not interfere with sperm quality-a preliminary long-term study. Reprod Sci. 2012;19(10):1057-62. https:// doi.org/10.1177/1933719112440747.

26. Lazaros L, Hatzi E, Markoula S, Takenaka A, Sofikitis N, Zikopoulos K, et al. Dramatic reduction in sperm parameters following bariatric surgery: report of two cases. Andrologia. 2012;44(6):428-32. https://doi.org/10.1111/j.1439-0272.2012. 01300.x.

27. Rato L, Alves MG, Cavaco JE, Oliveira PF. High-energy diets: a threat for male fertility? Obes Rev. 2014;15(12):996-1007. https:// doi.org/10.1111/obr.12226. Shows via an animal model a link between overconsumption of high-energy diets and harmful effects on the male reproductive system, including oxidative stress parameters.

28. Jensen TK, Heitmann BL, Blomberg Jensen M, Halldorsson TI, Andersson A-M, Skakkebaek NE, et al. High dietary intake of saturated fat is associated with reduced semen quality among 701 young Danish men from the general population. Am J Clin Nutr. 2013;97(2):411-8. https://doi.org/10.3945/ajen.112.042432.

29. Chavarro JE, Furtado J, Toth TL, Ford J, Keller M, Campos H, et al. Trans-fatty acid levels in sperm are associated with sperm concentration among men from an infertility clinic. Fertil Steril. 2011;95(5): 1794-7. https://doi.org/10.1016/j.fertnstert.2010.10.039.

30. Nguyen RH, Wilcox AJ, Skjaerven R, Baird DD. Men's body mass index and infertility. Hum Reprod. 2007;22(9):2488-93. https://doi. org/10.1093/humrep/dem139.

31. Ramlau-Hansen CH, Thulstrup AM, Nohr EA, Bonde JP, Sørensen TIA, Olsen J. Subfecundity in overweight and obese couples. Hum Reprod. 2007;22(6):1634-7. https://doi.org/10.1093/humrep/ dem035.

32. Bakos HW, Henshaw RC, Mitchell M, Lane M. Paternal body mass index is associated with decreased blastocyst development and reduced live birth rates following assisted reproductive technology. Fertil Steril. 2011;95(5):1700-4. https://doi.org/10.1016/j. fertnstert.2010.11.044.

33. Merhi ZO, Keltz J, Zapantis A, Younger J, Berger D, Lieman HJ, et al. Male adiposity impairs clinical pregnancy rate by in vitro fertilization without affecting day 3 embryo quality. Obesity. 2013;21(8):1608-12. https://doi.org/10.1002/oby.20164.

34. Cui H, Lopez M, Rahmouni K. The cellular and molecular bases of leptin and ghrelin resistance in obesity. Nat Rev Endocrinol. 2017;13(6):338-51. https://doi.org/10.1038/nrendo.2016.222.

35. Martins AD, Sa R, Monteiro MP, Barros A, Sousa M, Carvalho RA, et al. Ghrelin acts as energy status sensor of male reproduction by modulating Sertoli cells glycolytic metabolism and mitochondrial bioenergetics. Mol Cell Endocrinol. 2016;434:199-209. https://doi. org/10.1016/j.mce.2016.07.008.

36. Kahn BE, Brannigan RE. Obesity and male infertility. Curr Opin Urol. 2017;27(5):441-5. https://doi.org/10.1097/MOU. 0000000000000417.

37. Trayhurn P, Wood IS. Signalling role of adipose tissue: adipokines and inflammation in obesity. Biochem Soc Trans. 2005;33(Pt 5): 1078-81. https://doi.org/10.1042/BST20051078.

38. Reilly SM, Saltiel AR. Adapting to obesity with adipose tissue inflammation. Nat Rev Endocrinol. 2017. https://doi.org/10.1038/ nrendo.2017.90.

39. Engin A. The pathogenesis of obesity-associated adipose tissue inflammation. Adv Exp Med Biol. 2017;960:221-45. https://doi. org/10.1007/978-3-319-48382-5 9.

40. Guerrero-Bosagna C, Weeks S, Skinner MK. Identification of genomic features in environmentally induced epigenetic transgenerational inherited sperm epimutations. PLoS One. 2014;9(6):e100194. https://doi.org/10.1371/journal.pone.0100194.

41. Bohacek J, Mansuy IM. Molecular insights into transgenerational non-genetic inheritance of acquired behaviours. Nat Rev Genet. 2015;16(11):641-52. https://doi.org/10.1038/nrg3964.

42. Skinner MK, Guerrero-Bosagna C, Haque MM. Environmentally induced epigenetic transgenerational inheritance of sperm epimutations promote genetic mutations. Epigenetics: official journal of the DNA methylation. Society. 2015;10(8):762-71. https:// doi.org/10.1080/15592294.2015.1062207.

43. Jimenez-Chillaron JC, Nijland MJ, Ascensao AA, Sardao VA, Magalhaes J, Hitchler MJ, et al. Back to the future: transgenerational transmission of xenobiotic-induced epigenetic remodeling. Epigenetics: official journal of the DNA methylation. Society. 2015;10(4):259-73. https://doi.org/10.1080/15592294. 2015.1020267. 
44. Schagdarsurengin U, Steger K. Epigenetics in male reproduction: effect of paternal diet on sperm quality and offspring health. Nat Rev Urol. 2016;13(10):584-95. https://doi.org/10.1038/nrurol. 2016.157.

45. Miska EA, Ferguson-Smith AC. Transgenerational inheritance: models and mechanisms of non-DNA sequence-based inheritance. Science. 2016;354(6308):59-63. https://doi.org/10.1126/science. aaf4945.

46. Sharma U, Rando OJ. Metabolic inputs into the Epigenome. Cell Metab. 2017;25(3):544-58. https://doi.org/10.1016/j.cmet.2017. 02.003 .

47. Fullston T, McPherson NO, Zander-Fox D, Lane M. The most common vices of men can damage fertility and the health of the next generation. J Endocrinol. 2017;234(2):F1-6. https://doi.org/ 10.1530/JOE-16-0382.

48. Hur SS, Cropley JE, Suter CM. Paternal epigenetic programming: evolving metabolic disease risk. J Mol Endocrinol. 2017;58(3): R159-R68. https://doi.org/10.1530/JME-16-0236.

49. Evenson D, Wixon R. Meta-analysis of sperm DNA fragmentation using the sperm chromatin structure assay. Reprod BioMed Online. 2006;12(4):466-72. https://doi.org/10.1016/S1472-6483(10) 62000-7.

50. Kort HI, Massey JB, Elsner CW, Mitchell-Leef D, Shapiro DB, Witt MA, et al. Impact of body mass index values on sperm quantity and quality. J Androl. 2006;27(3):450-2. https://doi.org/10.2164/ jandrol.05124.

51. Chavarro JE, Toth TL, Wright DL, Meeker JD, Hauser R. Body mass index in relation to semen quality, sperm DNA integrity, and serum reproductive hormone levels among men attending an infertility clinic. Fertil Steril. 2010;93(7):2222-31. https://doi.org/10. 1016/j.fertnstert.2009.01.100.

52. Fariello RM, Pariz JR, Spaine DM, Cedenho AP, Bertolla RP, Fraietta R. Association between obesity and alteration of sperm DNA integrity and mitochondrial activity. BJU Int. 2012;110(6): 863-7. https://doi.org/10.1111/j.1464-410X.2011.10813.x.

53. Zini A, Boman JM, Belzile E, Ciampi A, Sperm DNA. Damage is associated with an increased risk of pregnancy loss after IVF and ICSI: systematic review and meta-analysis. Hum Reprod (Oxford, England). 2008;23(12):2663-8. https://doi.org/10.1093/humrep/ den321.

54. Sabeti P, Pourmasumi S, Rahiminia T, Akyash F, Talebi AR. Etiologies of sperm oxidative stress. Int J Reprod Biomed (Yazd, Iran). 2016;14(4):231-40.

55. Fedder J. Nonsperm cells in human semen: with special reference to seminal leukocytes and their possible influence on fertility. Arch Androl. 1996;36(1):41-65.

56. Sakkas D, Alvarez JG. Sperm DNA fragmentation: mechanisms of origin, impact on reproductive outcome, and analysis. Fertil Steril. 2010;93(4):1027-36. https://doi.org/10.1016/j. fertnstert.2009.10.046.

57. Chanseaume E, Tardy AL, Salles J, Giraudet C, Rousset P, Tissandier A, et al. Chronological approach of diet-induced alterations in muscle mitochondrial functions in rats. Obesity. 2007;15(1):50-9. https://doi.org/10.1038/oby.2007.511.

58. Rato L, Duarte AI, Tomas GD, Santos MS, Moreira PI, Socorro S, et al. Pre-diabetes alters testicular PGC1-alpha/SIRT3 axis modulating mitochondrial bioenergetics and oxidative stress. Biochim Biophys Acta. 2014;1837(3):335-44. https://doi.org/10.1016/j. bbabio.2013.12.008.

59. Tunc O, Bakos HW, Tremellen K. Impact of body mass index on seminal oxidative stress 322. Andrologia. 2011;43(1439-0272 (Electronic)):121-8.

60. Bakos HW, Mitchell M, Setchell BP, Lane M. The effect of paternal diet-induced obesity on sperm function and fertilization in a mouse model. Int J Androl. 2011;34(5 Pt 1):402-10. https://doi.org/10. 1111/j.1365-2605.2010.01092.x.
61. Koppers AJ, Garg ML, Aitken RJ. Stimulation of mitochondrial reactive oxygen species production by unesterified, unsaturated fatty acids in defective human spermatozoa. Free Radic Biol Med. 2010;48(1):112-9. https://doi.org/10.1016/j.freeradbiomed.2009. 10.033 .

62. Agarwal A, Saleh RA, Bedaiwy MA. Role of reactive oxygen species in the pathophysiology of human reproduction. Fertil Steril. 2003;79(4):829-43.

63. Ebisch IM, Thomas CM, Peters WH, Braat DD, SteegersTheunissen RP. The importance of folate, zinc and antioxidants in the pathogenesis and prevention of subfertility. Hum Reprod Update. 2007;13(2):163-74. https://doi.org/10.1093/humupd/ dml054.

64. Chiu YH, Afeiche MC, Gaskins AJ, Williams PL, Mendiola J, Jorgensen N, et al. Sugar-sweetened beverage intake in relation to semen quality and reproductive hormone levels in young men. Hum Reprod. 2014;29(7):1575-84. https://doi.org/10.1093/ humrep/deu102.

65. Kondaki K, Grammatikaki E, Jimenez-Pavon D, De Henauw S, Gonzalez-Gross M, Sjostrom M, et al. Daily sugar-sweetened beverage consumption and insulin resistance in European adolescents: the HELENA (healthy lifestyle in Europe by nutrition in adolescence) study. Public Health Nutr. 2013;16(3):479-86. https://doi. org/10.1017/S1368980012002613.

66. Evans JL, Goldfine ID, Maddux BA, Grodsky GM. Are oxidative stress-activated signaling pathways mediators of insulin resistance and beta-cell dysfunction? Diabetes. 2003;52(1):1-8.

67. Chen SJ, Allam JP, Duan YG, Haidl G. Influence of reactive oxygen species on human sperm functions and fertilizing capacity including therapeutical approaches. Arch Gynecol Obstet. 2013;288(1):191-9. https://doi.org/10.1007/s00404-013-2801-4.

68. Benedetti S, Tagliamonte MC, Catalani S, Primiterra M, Canestrari F, De Stefani S, et al. Differences in blood and semen oxidative status in fertile and infertile men, and their relationship with sperm quality. Reprod BioMed Online. 2012;25(3):300-6. https://doi.org/ 10.1016/j.rbmo.2012.05.011.

69. Ruff JS, Suchy AK, Hugentobler SA, Sosa MM, Schwartz BL, Morrison LC, et al. Human-relevant levels of added sugar consumption increase female mortality and lower male fitness in mice. Nat Commun. 2013;4:2245. https://doi.org/10.1038/ncomms3245.

70. Afanas'ev I. New nucleophilic mechanisms of ros-dependent epigenetic modifications: comparison of aging and cancer. Aging Dis. 2014;5(1):52-62. 10.14336/AD.2014.050052.

71. Tremellen K. Oxidative stress and male infertility-a clinical perspective. Hum Reprod Update. 2008;14(3):243-58. https://doi. org/10.1093/humupd/dmn004.

72. Moretti E, Collodel G, Mazzi L, Campagna M, Iacoponi F, Figura N. Resistin, interleukin-6, tumor necrosis factor-alpha, and human semen parameters in the presence of leukocytospermia, smoking habit, and varicocele. Fertil Steril. 2014;102(2):354-60. https:// doi.org/10.1016/j.fertnstert.2014.04.017.

73. Ng SF, Lin RC, Laybutt DR, Barres R, Owens JA, Morris MJ. Chronic high-fat diet in fathers programs beta-cell dysfunction in female rat offspring. Nature. 2010;467(7318):963-6.

74. Ng SF, Lin RC, Maloney CA, Youngson NA, Owens JA, Morris MJ. Paternal high-fat diet consumption induces common changes in the transcriptomes of retroperitoneal adipose and pancreatic islet tissues in female rat offspring. FASEB J. 2014;28(4):1830-41. https://doi.org/10.1096/fj.13-244046.

75. Fullston T, Ohlsson Teague EM, Palmer NO, Deblasio MJ, Mitchell $\mathrm{M}$, Corbett $\mathrm{M}$, et al. Paternal obesity initiates metabolic disturbances in two generations of mice with incomplete penetrance to the F2 generation and alters the transcriptional profile of testis and sperm microRNA content. FASEB J. 2013;27(10):4226-43. https:// doi.org/10.1096/fj.12-224048. 
76. Palmer NO, Fullston T, Mitchell M, Setchell BP, Lane M. SIRT6 in mouse spermatogenesis is modulated by diet-induced obesity. Reprod Fertil Dev. 2011;23(7):929-39. https://doi.org/10.1071/ RD10326.

77. Terashima M, Barbour S, Ren J, Yu W, Han Y, Muegge K. Effect of high fat diet on paternal sperm histone distribution and male offspring liver gene expression. Epigenetics: official journal of the DNA methylation. Society. 2015;10(9):861-71. https://doi.org/10. 1080/15592294.2015.1075691.

78. Sharma U, Conine CC, Shea JM, Boskovic A, Derr AG, Bing XY, et al. Biogenesis and function of tRNA fragments during sperm maturation and fertilization in mammals. Science. 2016;351(6271):3916. https://doi.org/10.1126/science.aad6780.

79.• Grandjean V, Fourre S, De Abreu DA, Derieppe MA, Remy JJ, Rassoulzadegan M. RNA-mediated paternal heredity of dietinduced obesity and metabolic disorders. Sci Rep. 2015;5:18193. https://doi.org/10.1038/srep18193. To our knowledge, the first paper providing evidence that RNA could serve as a vector to transfer nutrition-related message to the offspring.

80. Chen Q, Yan M, Cao Z, Li X, Zhang Y, Shi J, et al. Sperm tsRNAs contribute to intergenerational inheritance of an acquired metabolic disorder. Science. 2016;351(6271):397-400. https://doi.org/10. 1126/science.aad7977. Shows that the nearly forgotten tsRNAs are epigenetic messengers as well.

81. Consales C, Leter G, Bonde JP, Toft G, Eleuteri P, Moccia T, et al. Indices of methylation in sperm DNA from fertile men differ between distinct geographical regions. Hum Reprod. 2014;29(9): 2065-72. https://doi.org/10.1093/humrep/deu176.
82. Soubry A, Guo L, Huang Z, Hoyo C, Romanus S, Price T, et al. Obesity-related DNA methylation at imprinted genes in human sperm: results from the TIEGER study. Clin Epigenetics. 2016;8: 51. https://doi.org/10.1186/s13148-016-0217-2. Shows methylation differences in obese versus normal weight men at imprint regulatory regions, which are important for early embryo growth.

83. Donkin I, Versteyhe S, Ingerslev LR, Qian K, Mechta M, Nordkap $\mathrm{L}$, et al. Obesity and bariatric surgery drive epigenetic variation of spermatozoa in humans. Cell Metab. 2015. https://doi.org/10.1016/ j.cmet.2015.11.004. Presents a comprehensive epigenetic analysis on sperm cells from obese men, before and after bariatric surgery.

84. Manikkam M, Guerrero-Bosagna C, Tracey R, Haque MM, Skinner MK. Transgenerational actions of environmental compounds on reproductive disease and identification of epigenetic biomarkers of ancestral exposures. PLoS One. 2012;7(2):e31901. https://doi.org/10.1371/journal.pone.0031901.

85. Soubry A, Schildkraut JM, Murtha A, Wang F, Huang Z, Bernal A, et al. Paternal obesity is associated with IGF2 hypomethylation in newborns: results from a newborn epigenetics study (NEST) cohort. BMC Med. 2013;11:29. https://doi.org/10.1186/1741-701511-29. First indication in humans for an epigenetic effect from paternal obesity on offspring.

86. Soubry A, Murphy SK, Wang F, Huang Z, Vidal AC, Fuemmeler $\mathrm{BF}$, et al. Newborns of obese parents have altered DNA methylation patterns at imprinted genes. Int J Obes. 2013. https://doi.org/10. 1038/ijo.2013.193. 